\title{
Combating global challenges - climate change, biodiversity loss and poverty simultaneously: Unachievable goal or the only way forward?
}

\author{
Denis Vasiliev ${ }^{l, *}$ \\ ${ }^{1}$ Turiba University, Faculty of Business and Administration, 68 Graudu Street, Riga, LV-1058, Latvia
}

\begin{abstract}
Research background: Globally climate action is gaining momentum. Most significant players on global political arena including the US, the EU and China are actively engaging in addressing the problem of climate change. Sustainable development agenda implies the need to simultaneously reduce harmful impacts of anthropogenic activity on natural ecosystems, reduce poverty and combat global heating. However, when pursuing these three targets often complicated trade-offs emerge. These trade-offs are especially pronounced when competing land-uses are considered. Recent global assessments suggest that the world is failing to slow down biodiversity loss, poverty is going to soar in the nearest future, and global heating is likely to reach temperature limit. All these problems need to be addressed in nearest few decades. The task may seem overwhelming, especially without a clear roadmap.

Purpose of the article: The aim of this study is to critically evaluate approaches to climate mitigation, detect trade-offs and synergies with biodiversity conservation and poverty alleviation goals and find the optimal strategies capable to resolve all these problems together.

Methods: Conceptual research approach - theory adaptation was used.

Findings \& Value added: Findings of present study suggest that in order to achieve sustainable development only climate actions that benefit biodiversity conservation should be implemented. In case biodiversity is supported by global initiatives it is likely that poverty will be reduced due to sustained provision of ecosystem services, underpinning human wellbeing. Policy recommendations are provided that could help tailoring climate actions to support biodiversity conservation and reduce poverty.
\end{abstract}

Keywords: sustainable development; climate policy; general welfare; natural resource economics; poverty alleviation

JEL Classification: Q540; Q580; I310; I380; O210

\footnotetext{
*Corresponding author: denisksil@gmail.com
} 


\section{Introduction}

Sustainable development implies fostering development of human society without compromising ability of natural ecosystems to regenerate resources and provide ecosystem services (Mebratu, 1998). The idea is not new and exists in its present form since the 1972 United Nations (UN) Conference on Human Environment in Stockholm. In 2015 the UN Global assembly has set up a blueprint for achievement of global sustainable development in a form of seventeen goals that have to be achieved by 2030, called "Sustainable Development Goals" (SDGs) (The UN, 2021). In essence the goals aim to tackle main global problems poverty, climate change and biodiversity loss simultaneously, and to achieve humanwellbeing across the globe. The intention is very ambitious, and it has fostered an active debate in global scientific community (Eskelinen, 2021). It is often suggested that the idea is utopic, and the gals are unachievable. Indeed, serious trade-offs exist between achievement of economic development and nature conservation, as economic growth is usually based on resource exploitation. For instance, infrastructure construction is a backbone of robust economic development of a country, but such anthropogenic intervention into natural ecosystems may be detrimental for biodiversity. Moreover, trade-offs exist even between goals that seem to be synergistic, namely a goal to address climate change and to reserve nature. For instance, growing biofuels requires large areas of land and these land-uses compete for area with the natural ecosystems. Achievement of SDGs seems to be particularly challenging today. Current state of climate requires urgent coordinate global action to prevent catastrophic outcomes (IPCC, 2021). Biodiversity decline rates are dramatic also requiring immediate globally coordinated action (CBD, 2020). Finally, global poverty has already rose sharply and is expected to rise further as a consequence of COVID-19 pandemic (The World Bank, 2020).

Apparently, the main focus of current high profile political activity is climate change mitigation, with recently launched ambitious European Green Deal aiming to make the EU carbon neutral by 2050, the US Climate 2030 Greenhouse Gas Pollution Reduction Target aiming to slash emissions in the USA by half and Chinese pledge to achieving carbon neutrality by 2060 and boosting forest coverage by 6 billion cubic meters by 2030 . What is worrying, however, about these initiatives is that although their positive contribution to biodiversity conservation and human well-being is mentioned, there are no clear safe-guards for climate mitigation goals not to override the other two priorities. Furthermore, lack of cooperation and coordinated actions on development of biodiversity and social-integrity safeguards may lead to dramatic consequences and actually do more harm than good. To void such outcome and truly achieve SDGs it is essential to understand trade-offs and synergies between climate change mitigation strategies, biodiversity conservation and economic development. Global governance mechanisms also need to be considered, as without proper enforcement legal frameworks are unlikely to work and deliver any benefit (Coscieme et al., 2020). Possible indirect side effect of climate policies needs to be critically evaluated. Issues associated with global climate change mitigation initiatives re actively discussed in scientific literature. Despite this, current high profile climate policy frameworks, including those that emerged recently still tend to lack mechanisms of integration for other aspects of sustainable development, especially biodiversity conservation, and safeguards for protecting nature and society against possible negative impacts of climate action are clearly missing. Application of adaptive governance approaches, that could resolve ck of coordination among different policies, tend to demonstrate success a smaller scale and are lacking mechanisms that could help to operationalize them at a lobal scale. Exclusive focus of media on climate-change issues, tends to distort attention of the larger society from problems of biodiversity and poverty in the Global South. Lack of awareness and clarity is likely to lead key stakeholders to make wrong choices when it comes to trade-off between climate change mitigation and biodiversity or well-being of society in less developed regions. Thus, the aim of study is to 
critically evaluate approaches to climate mitigation, detect trade-offs and synergies with biodiversity conservation and poverty alleviation goals and find the optimal strategies capable to resolve all these problems together.

\section{Methods}

It was decided to use conceptual research methodology in this study. This methodology was chosen, because it allows conducting interdisciplinary research and finding solutions to realworld problems. There are four approaches to conceptual research including: theory synthesis, theory adaptation, typology, and modelling (Jaakkola, 2020). Theory synthesis is based purely on existing theories, while theory adaptation aims to bridge theory and its application from a range of disciplines. Typology approach aims to extract key concepts from a range of theories and arrange them into a logical framework, while modelling approach is based on prediction of relationships between multiple concepts. In present study theory adaptation approach was chosen as it aims bridge theory and practice from across disciplines, this way proposing novel insights. This is exactly what is essential in order to envisage the way to achievement of SDGs at global scale. Conceptual research in present study is applied at the interface of climate governance, environmental governance, social sciences, and environmental economy. This allows identifying key trade-offs and synergies between aspects of implementation of climate adaptation, biodiversity conservation and poverty reduction strategies. It also allows proposing the way how SDGs can be achieved at a global sale. The approach allows proposing evidence based policy recommendations and indicate further research directions.

\section{Results and Discussion}

\subsection{Key trade-off areas}

Biodiversity is central to web of life, Paterson et al., 2008) and it underpins delivery of ecosystem services, which in turn underpin human wellbeing. At certain biodiversity loss thresholds survival of humanity may be under threat. For instance, widespread decline of pollinator insect diversity may soon undermine delivery of pollination ecosystem services and ultimately lead to a substantial threat for human food security. Yet, despite the fact that biodiversity is central to sustaining ecological processes that actually underpin human life, it often receives less attention in policies focusing on climate change mitigation. Indeed, it is often emphasised that climate change is a threat for biodiversity, which is the case. However, climate mitigation measures often threaten biodiversity more than the global heating itself (Paterson et al., 2008). Trade-offs between biodiversity conservation goals and climate mitigation goals usually arise when it comes to production of renewable energy. Among the key issues are competition for land and landscape homogenisation arising from growing biofuels and establishing carbon-sink tree plantations, with potentially detrimental consequences for natural ecosystems. The problem is really global. Multiple high profile global tree planting initiatives such as Bonn Challenge, Trillion Tree Campaign and China's Billion Tree project are currently underway. These initiatives intend to create carbon-sink forest plantations on degraded lands. However, evidence suggests that quite often especially in tropics plantations replace natural habitats leading to landscape homogenization and biodiversity loss (Veldman et al., 2019). Situation with growing biofuels is even more dramatic, as the projects usually even do not include intent to be planted on degraded lands. Instead, biofuel cultures such as rape seed in temperate zone and oil palm and sugarcane in tropics require fertile lands. Thus, biofuel production competes with agriculture and 
natural/semi-natural ecosystems for land area. In tropics this leads to dramatic deforestation. For instance, area of land expected to be used for biofuel production in Malaysia and Indonesia is expected to exceed 25 million hectares by 2025 (Khatiwada et al., 2021). Similarly, in sugar cane production surge is expected Brazil putting the Amazon and Pantanal biomes under threat (Junior et al., 2020).

Along with competition for land climate mitigation measures have a range of other implications threatening biodiversity. These problems are associated with production with electricity. Hydroelectric dams play an important role in supply of electrical energy and currently represents more than two-thirds of total global renewable energy supply. Construction of the dams is likely to increase with dramatically increasing demand for renewables in the context of climate change mitigation. However, it is well established that river dam construction leads to dramatic losses of both terrestrial and aquatic biodiversity (Ezcurra et al. 2019). Thee impacts may be particularly damaging as large sale development projects are expected to take place in the Global South, where biodiversity is particularly high. Another important source of renewable energy is wind power. Although this energy source currently represents less than one fifth of the global renewable energy supply, demand for wind power fuelled by climate change mitigation policies is one of the fastest growing over the last two decades. Wind power stations, however, are also causing damage to biodiversity especially to birds and flying animals (Tesfahunegy et al., 2020). Other renewable energy sources, uh as solar, ocean and geothermal energy are often considered to be relatively safe for biodiversity. However, construction of stations for sourcing these energy types are often associated with natural habitat loss, degradation and pollution (Gasparatos et al., 2017).

Along with trade-offs between biodiversity conservation and climate strategies discussed above, climate change mitigation may also have adverse impacts on local communities. Rights of indigenous peoples are often disrespected when it comes to large scale land use decisions (Bayrak \& Marafa, 2016). This may have particularly dramatic consequences in countries of the Global South where regulatory frameworks are weak. Land conversion for carbon-sink plantations, growth of biofuels or construction of renewable energy plants may form attractive opportunities for 'green grabbing', which involves appropriation of land, secularization of resources and displacement of marginalizing poor and vulnerable communities harnessing support from by climate change mitigation and environmental funds and legislation (Veldman et al., 2019). Displacement of local communities may also have negative feedback on biodiversity, as attempts to find alternative fishing or hunting areas my lead to intervention into wild and intact ecosystems. Even projects that officially involve some sort of interaction with local communities may actually reduce involvement of indigenous peoples to programmatic formalities instead of real negotiations, which ultimately may lead to damaging consequences for local society. This may indeed exacerbate poverty leading to situations where some people benefit at the expense of others. In fact, climate change mitigation strategies even when biodiversity aspects are considered may lead to displacement of local communities, or even can deliver benefits to local communities but impose costs to communities elsewhere (Chausson et al., 2020). For instance, construction of hydroelectric dams may improve lives of certain communities by providing access to electrical energy and creating local jobs but derive downstream communities from fishing opportunity on which their livelihoods depend. Furthermore, rapid transition to carbon neutrality, which implies carbon taxes on businesses, is likely to contribute to inflation and costs that will be passed down the supply chain to consumers, ultimately worsening global poverty. Transition to renewable energy without robust financial support mechanisms is also likely to impose cost burdens on local communities depending on cheaper energy sources such as firewood. 


\subsection{Key synergies}

Despite trade-offs discussed above, there are evident synergies between climate change mitigation and both biodiversity conservation and poverty alleviation. Furthermore, there are synergies between poverty alleviation and biodiversity conservation, too. However, unlike trade-offs synergies are emphasised in media and in policy documents, which to some extent overshades complexity of the links between the three areas of sustainable development. Considering synergies between climate change mitigation and biodiversity conservation it is first of all important to point out that climate change is one of the most important drivers of biodiversity loss. Empirical evidence suggests that substantial extinction debt (i.e., delayed extinctions) in many species is caused by global heating (Kuussaari et al., 2009). Although, throughout palaeontological epochs species survived multiple climate changes, global heating in Anthropocene is too rapid to allow many species to adapt. Impacts of climate change are also exacerbated by the fact that it affects species in synergy with other drivers of biodiversity decline. Globally landscape is strongly fragmented, and fragmentation continues especially in developing countries, depriving species from the opportunity to adapt to changing climate conditions through range-shifts. Furthermore, climate change promotes proliferation of invasive non-native species, fosters eutrophication and induces pollutant mobilization and increases their toxicity negatively affecting biodiversity (Kibria et al., 2021). So, there is no doubt that climate change needs to be addressed in order to ensure success of biodiversity conservation efforts. However, this needs to be done applying measures that do not compromise biodiversity. Otherwise, benefits from climate mitigation will be substantially reduced if not completely cancelled.

Synergies between climate change mitigation and poverty alleviation are also evident. First of all, the former is expected to create so called "green jobs" (Hongtao, 2013), which may substantially boost economies globally. Furthermore, the positive impact of climate change mitigation on natural ecosystems is likely to deliver benefits to society through sustainable flow of ecosystem services, which underpin human well-being and are especially important in sustaining livelihoods of local communities in the Global South. Indeed, human food security heavily depends on ecosystem health and climate change mitigation can contribute to both, reducing risks of famine and extreme poverty. Water security also is likely to increase due to climate change mitigation as global heating actually cause extreme droughts. Desertification driven by climate change deprives many people from land and resources, thereby exacerbating global poverty. Furthermore, climate disasters (e.g., floods and hurricanes) that happen increasingly frequently under global climate change and rising sea levels lead to increasing migration of people - climate refugees, who lost shelter and food and are forced to seek asylum in other countries. If global warming will be addressed, such disastrous events are likely to become rarer and this way global poverty alleviation goals can be better met. In addition to that global heating fosters proliferation of pests and diseases. Spread of pests directly threatens human food security affecting both developing and developed countries. Even pandemics, such as COVID-19 may be associated with global heating and climate change mitigation is likely to reduce risks of pandemics in future, this way contributing to human well-being and health of global economy. Also, production of renewable energy in the context of fossil fuel run out is likely to save humanity from energy poverty (Chakravarty \& Tavoni, 2013). Climate change mitigation may also involve gender equality, as access to clean energy is likely to deliver benefits to women in developing countries as activities such as cooking on coal and firewood collection that are harmful for health and time consuming will be made redundant. Finally, it is important to note, that positive feedback exists between poverty alleviation and success of climate change mitigation strategies, as the latter are likely to be sustainable in long term only in case support from local communities is secured. So, overall synergies between climate change mitigation and poverty alleviation can be significant. However, similar to situation with biodiversity 
conservation, trade-offs if not addressed may substantially limit the benefits and undermine global huma well-being.

\subsection{The way forward}

As follows from above discussion meeting all three key areas of sustainable development is the only way forward. However, trade-offs between climate change mitigation and any of the other two areas (nature conservation and poverty alleviation) can totally undermine success of achieving SDGs. In order, to understand how to find the right balance, it is essential to recall relationship between the three pillars of sustainability: environment, society and economy (Purvis et al., 2019). Namely, natural environment is of a paramount importance and without its health neither society nor economy are likely to be developing in a long term (Purvis et al., 2019). Now, considering relationships between climate-change mitigation and nature conservation, it is obvious that if the former undermines the latter, sustainable development is doomed. However, the relationship here is even more complicated, because without climate change mitigation success, nature conversion is unlikely to succeed either. Still, what is straightforward that current focus on climate change mitigation without considering biodiversity, is likely to lead to trade-offs undermining biodiversity and ecosystem integrity. So, how can this be resolved? Actually, as synergies between climate change mitigation and biodiversity conservation exist and the main area of trade-offs lays in competition for land two thing are likely to resolve this conflict. First of all, biodiversity conservation rather than climate change mitigation has to be considered the first priority. Thus, robust biodiversity safeguards have to be integrated in all climate change mitigation strategies. This would motivate key stakeholders to choose climate change mitigation measures that do not harm biodiversity over those that do. Secondly, landscape scale integrated planning is needed as it can resolve conflicts between different land uses (Mann et al., 2018). For instance, carbon-sink plantations may be established on degraded lands or be used as a part of forest restoration strategies that consider aspects of biodiversity. Solar or hydro power plants may also be located in areas that do not harm biodiversity. The use of biofuels needs to be carefully considered, giving priority to fuels originating from waste rather than those competing for fertile lands with agriculture and natural ecosystems. Furthermore, gradual phasing out of fossil fuels and use of nuclear energy in combination with renewables is likely to cause less harm to biodiversity than sharp switch to renewables.

Considering discussed above social aspects, it also becomes obvious that climate mitigation is essential for sustainable development in this area. However, similar to nature conservation, poverty alleviation has trade-offs with climate strategies. Undermining social integrity is likely to limit benefits from climate change mitigation and to make achievements in the area of climate unsustainable in longer term. So, a clear balance needs to be struck between climate change mitigation and social development goals. Here, integrated landscape scale planning can be helpful, too (Mann et al., 2018), as it could resolve conflicts between local communities and climate mitigation land-uses. However, the approach is unlikely to deliver substantial benefits without involvement of local communities and indigenous peoples in decision making. Involvement of locals is fundamental to success both for climate change mitigation and nature conservation outcomes, as local people possess deep knowledge of local ecosystems. Their livelihoods may be indeed enhanced by discussed above synergies, such as green jobs and access to clean energy, making achieving their support relatively easy. So, social safeguards urgently need to be integrated into climate mitigation strategies, too. Application of modern information technologies have capabilities to improve implementation of both communication and planning processes, thereby significantly contributing to achievement of SDGs (Eteris, 2020). Thus, achievement of the three key areas of sustainable development is possible, but it requires shift from exclusive 
focus on climate change mitigation to holistic approach incorporating biodiversity conservation and poverty alleviation priorities and avoiding trade-offs (Figure 1).

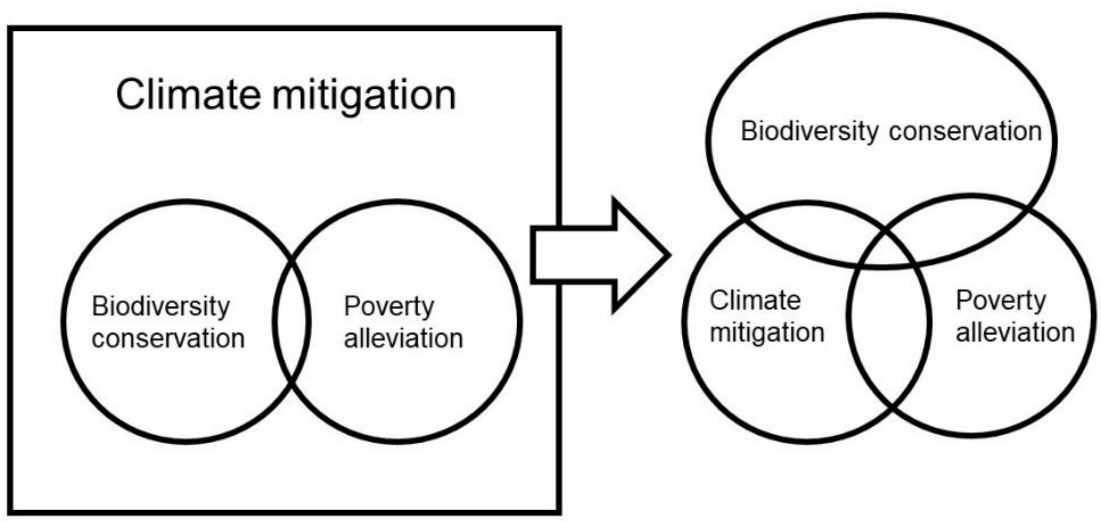

a

Figure 1. Finding balance between climate change mitigation, biodiversity conservation and poverty alleviation (Based on Purvis et al., 2019). Focus should be shifted from: a) prioritising climate change over biodiversity and social well-being, to b) prioritising biodiversity conservation and finding the right balance between poverty alleviation and climate change mitigation.

It has to be clearly communicated to decision makers that climate change mitigation strategies that override biodiversity conservation and are not integrated with social wellbeing goals should not be even considered. Current overwhelming focus on climate (Figure 1a) is indeed dangerous and need to be shifted towards understanding that without ecosystem integrity and social benefits it will not lead to achievement of SDGs. However, it also has to be clearly understood, that the only way forward it to find the synergies between the three key areas of sustainable development and in cases when trade-offs emerge, biodiversity should and social benefits should not be overridden by climate goals (Figure 1b). This is feasible but right priorities shout be set at the beginning of any climate change mitigation initiative.

\section{Conclusions}

The aim of this study was to is to critically evaluate approaches to climate mitigation, detect trade-offs and synergies with biodiversity conservation and poverty alleviation goals and find the optimal strategies capable to resolve all these problems together. It was found that tradeoffs between the three areas mainly arise as a result of conflicting land-use goals. Due to substantial synergies between climate mitigation, biodiversity conservation and poverty alleviation, it is possible to achieve success in all three areas simultaneously. This would require integrated land-use planning, involvement of local communities in decision making and avoiding situations when climate change mitigation activities override biodiversity conservation goals or social integrity. To achieve this robust biodiversity and social safeguards need to be integrated into climate mitigation strategies. 


\section{References}

1. Bayrak, M. M., \& Marafa, L. M. (2016). Ten years of REDD+: A critical review of the impact of REDD+ on forest-dependent communities. Sustainability, 8(7), 620.

2. CBD (2020). Global Biodiversity Outlook 5. Secretariat of the Convention on Biological Diversity.

3. Chakravarty, S. and Tavoni, M. (2013). Energy poverty alleviation and climate change mitigation: Is there a trade off? Energy Economics, 40, S67-S73.

4. Chausson, A., Turner, B., Seddon, D., Chabaneix, N., Girardin, C. A., Kapos, V., ... \& Seddon, N. (2020). Mapping the effectiveness of nature-based solutions for climate change adaptation. Global Change Biology, 26(11), 6134-6155.

5. Coscieme, L., da Silva Hyldmo, H., Fernández-Llamazares, Á., Palomo, I., Mwampamba, T. H., Selomane, O., ... \& Valle, M. (2020). Multiple conceptualizations of nature are key to inclusivity and legitimacy in global environmental governance. Environmental Science \& Policy, 104, 36-42.

6. de Andrade Junior, M. A., Maxwell, S. L., \& Watson, J. E. (2020). Renewed threats to Brazilian biodiversity from sugarcane. Frontiers in Ecology and the Environment, 18(4), 178-179.

7. Eskelinen, T. (2021). Interpreting the Sustainable Development Goals through the Perspectives of Utopia and Governance. Forum for Development Studies, 48(2), 179197.

8. Eteris, E. (2020). Sustainability and digitalization: double strategy guidelines in national development. Acta Prosperitatis, (11), 42-185.

9. Ezcurra, E., Barrios, E., Ezcurra, P., Ezcurra, A., Vanderplank, S., Vidal, O., ... \& Aburto-Oropeza, O. (2019). A natural experiment reveals the impact of hydroelectric dams on the estuaries of tropical rivers. Science advances, 5(3), eaau9875.

10. Gasparatos, A., Doll, C. N., Esteban, M., Ahmed, A., \& Olang, T. A. (2017). Renewable energy and biodiversity: Implications for transitioning to a Green Economy. Renewable and Sustainable Energy Reviews, 70, 161-184.

11. Hongtao, Y. (2013). Clean energy policies and green jobs: An evaluation of green jobs in U.S. metropolitan areas. Energy Policy, 56, 644-652.

12. IPCC (2021). Summary for Policymakers. In: Climate Change 2021: The Physical Science Basis. Contribution of Working Group I to the Sixth Assessment Report of the Intergovernmental Panel on Climate Change [Masson-Delmotte, V. et al. (eds.)]. Cambridge University Press. In Press.

13. Jaakkola, E. (2020). Designing conceptual articles: four approaches. AMS review, 10(1), $18-26$.

14. Khatiwada, D., Palmen, C., \& Silveira, S. (2021). Evaluating the palm oil demand in Indonesia: production trends, yields, and emerging issues. Biofuels, 12(2), 135-147.

15. Kibria, G., Nugegoda, D., Rose, G., \& Haroon, A. Y. (2021). Climate change impacts on pollutants mobilization and interactive effects of climate change and pollutants on toxicity and bioaccumulation of pollutants in estuarine and marine biota and linkage to seafood security. Marine Pollution Bulletin, 167, 112364.

16. Kuussaari, M., Bommarco, R., Heikkinen, R. K., Helm, A., Krauss, J., Lindborg, R., ... \& Steffan-Dewenter, I. (2009). Extinction debt: a challenge for biodiversity conservation. Trends in ecology \& evolution, 24(10), 564-571. 
17. Mann, C. et al. (2018). The potential for integrated landscape management to fulfil Europe's commitments to the Sustainable Development Goals. Landscape and Urban Planning, 177, 75-82.

18. Mebratu, D. (1998). Sustainability and sustainable development: historical and conceptual review. Environmental impact assessment review, 18(6), 493-520.

19. Paterson, J. S., Araújo, M. B., Berry, P. M., Piper, J. M., \& Rounsevell, M. D. (2008). Mitigation, adaptation, and the threat to biodiversity. Conservation Biology, 22(5), 1352-1355.

20. Purvis, B., Mao, Y., \& Robinson, D. (2019). Three pillars of sustainability: in search of conceptual origins. Sustainability science, 14(3), 681-695.

21. Tesfahunegny, W., Datiko, D., Wale, M., Hailay, G. E., \& Hunduma, T. (2020). Impact of wind energy development on birds and bats: the case of Adama wind farm, Central Ethiopia. The Journal of Basic and Applied Zoology, 81(1), 1-9.

22. The UN (2021) 17 Goals to Transform Our World. The United Nations. https://www.un.org/sustainabledevelopment/

23. The World Bank (2020). Poverty. The World Bank. https://www.worldbank.org/en/topic/poverty/overview

24. Veldman, J. W., Aleman, J. C., Alvarado, S. T., Anderson, T. M., Archibald, S., Bond, W. J., ... \& Zaloumis, N. P. (2019). Comment on "The global tree restoration potential". Science, 366(6463). 